\title{
Lung cancer screening is here to stay, but does it pay?
}

\author{
Christopher W. Seder, MD
}

From the Department of Cardiovascular and Thoracic Surgery, Rush University Medical Center, Chicago, Ill. Disclosures: Author has nothing to disclose with regard to commercial support.

Received for publication Aug 30, 2017; accepted for publication Sept 2, 2017; available ahead of print Sept 28, 2017.

Address for reprints: Christopher W. Seder, MD, 1725 W Harrison St, Ste 774, Chicago, IL 60612 (E-mail: christopher_w_seder@rush.edu).

J Thorac Cardiovasc Surg 2018;155:426-7

0022-5223/\$36.00

Copyright (c 2017 by The American Association for Thoracic Surgery

http://dx.doi.org/10.1016/j.jtcvs.2017.09.006

In 2011, the National Lung Cancer Screening Trial reported a $20 \%$ reduction in lung cancer mortality and a $6.7 \%$ reduction in all-cause mortality with annual low-dose computed tomography compared with chest radiograph in high-risk patients. ${ }^{1}$ Accordingly, the Centers for Medicare \& Medicaid Services approved payment in appropriately selected groups. ${ }^{2}$ This has led to the widespread implementation of lung cancer screening programs across the United States and will likely result in the identification of more early-stage lung cancers than ever before. Although the cost-effectiveness of low-dose computed tomography screening on a societal level remains strongly debated, ${ }^{3}$ most hospital administrators are singularly focused on the financial implications for their individual institutions.

The article by Gilbert and colleagues ${ }^{4}$ attempts to address this issue by quantifying the financial influence of a nurse practitioner-directed lung cancer screening, incidental pulmonary nodule, and tobacco cessation clinic on a hospital system. Between 2013 and 2016, nearly 700 patients were seen in the clinic, three-quarters of whom were enrolled in the lung cancer screening program. The authors highlight that when fiscal success is defined using the narrow lens of nurse practitioner salary plus benefits versus professional billing revenue, the clinic operates at a loss. However, when the larger economic influence on the division and hospital are considered, the clinic is a financially sound endeavor.

The accurate calculation of net revenue generated by the clinic is somewhat limited by the study's methodology. Specifically, only a portion of the downstream revenue potentially produced through the clinic was captured. Income generated from ancillary testing (eg, pulmonary function testing, computed tomography, positron emission tomography scans, and brain magnetic resonance imaging) and nonsurgical therapies (eg, induction and adjuvant chemotherapy and radiation therapy) were not included in the analysis. In addition, patients who qualify for lung cancer screening often have multiple health problems. A positive experience with a lung cancer screening program may serve as a solid entry point into a health care system,

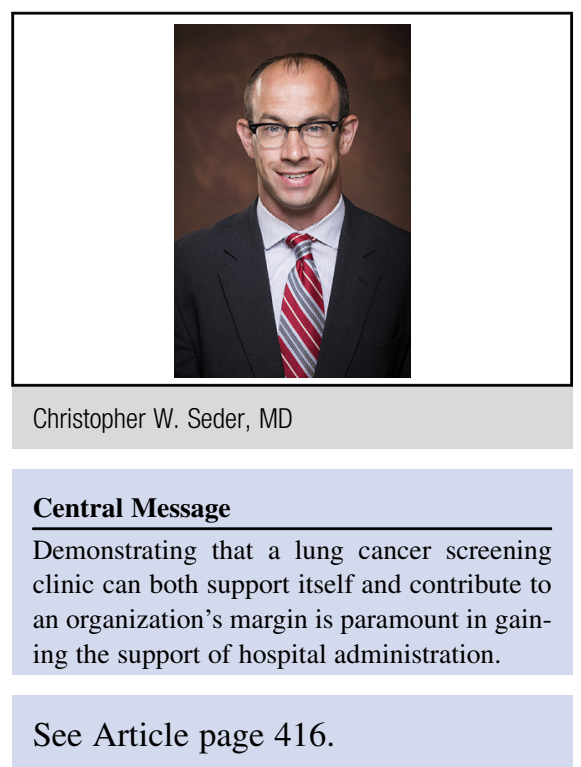

generating additional downstream revenue for that organization. The authors did not include these potential sources of income in the analysis because they are often difficult to accurately track. Despite this, they were still able to demonstrate that the clinic operates with a net gain.

It is unclear whether a nurse practitioner-directed clinic model is generalizable across the nation. State regulations guide the autonomy of individual health care providers and, in some regions, nurse practitioners must still operate with the oversight of a physician - adding to the cost of such a clinic. In addition, payer mix will certainly influence the revenue generated by such a clinic. Despite these variables, this article by Gilbert and colleagues ${ }^{4}$ is an important contribution to the literature at a time when hospital resources are tightly guarded and return on investment is heavily scrutinized.

Demonstrating that a lung cancer screening clinic can not only support itself, but also potentially contribute to the organization's margin, is paramount in gaining the attention and support of hospital administration. As we continue to weigh the cost-effectiveness of lung cancer screening on a societal and local level, Gilbert and colleagues ${ }^{4}$ should be congratulated for bringing us 1 step closer with this study.

\footnotetext{
References

1. National Lung Cancer Screening Team, Aberle DR, Adams AM, Berg CD, Black WC, Clapp JD, Fagerstrom RM, et al. Reduced lung-cancer mortality with low-dose computed tomographic screening. N Engl J Med. 2011;365: 395-409.

2. Mulshine JL, D'Amico TA. Issues with implementing a high-quality lung cancer screening program. CA Cancer J Clin. 2014;64:352-63.
} 
3. Black WC, Gareen IF, Soneji SS, Sick JD, Keeler EB, Aberle DR, et al. Cost-effectiveness of CT screening in the National Lung Screening Trial. N Engl J Med. 2014;371:1793-802.
4. Gilbert CR, Ely R, Fathi JT, Louie BE, Wilshire CL, Modin H, et al. The economic impact of a nurse practitioner-directed lung cancer screening, incidental pulmonary nodule, and tobacco-cessation clinic. J Thorac Cardiovasc Surg. 2018;155:416-24. 